\title{
A Compact MultiBand and Dual-Polarized Mobile Base-Station Antenna Using Optimal Array Structure
}

\author{
Young-Bae Jung ${ }^{1}$ and Soon-Young Eom ${ }^{2}$ \\ ${ }^{1}$ Department of Electronics and Control Engineering, Hanbat National University, 16-1 Duckmyong-dong, Yuseong-gu, \\ Dajeon 305-700, Republic of Korea \\ ${ }^{2}$ Radio Technology Research Department, Electronics and Telecommunications Research Institute, 138 Gajeong-no, \\ Yuseong-gu, Dajeon 305-719, Republic of Korea \\ Correspondence should be addressed to Soon-Young Eom; syeom@etri.re.kr
}

Received 25 November 2014; Revised 6 March 2015; Accepted 13 March 2015

Academic Editor: Luis Landesa

Copyright (C) 2015 Y.-B. Jung and S.-Y. Eom. This is an open access article distributed under the Creative Commons Attribution License, which permits unrestricted use, distribution, and reproduction in any medium, provided the original work is properly cited.

\begin{abstract}
This paper introduces a multiband base-station antenna to provide multiple communications services. There is growing need for multiband base-station antennas for mobile communications to serve existing 2nd and 3rd generation systems and to provide emerging 4th generation communication service as well as WiFi. For example, cellular, PCS, and especially WCDMA service are currently widely used in Korea, and 4th generation service (WiBro and LTE), introduced in 2011, will have to operate in parallel with existing services. The proposed multiband base-station antenna can provide a single/dual/triple or more multiple services using dual-polarization ( $\pm 45^{\circ}$ linear polarizations) according to the requirements of the service provider. This antenna has a shared aperture, having several array antenna sets for multiple services (Band 1: cellular service in 0.824 0.894 GHz, Band 2: PCS, WCDMA, and WiFi in 1.920 2.170 GHz, Band 3: WiBro and WiMAX in 2.300 2.400 GHz, and Band 4: WiMAX in $5.150 \sim 5.850 \mathrm{GHz})$. This antenna can be helpful for reducing base-station operating expenses and to create a clean urban landscape by minimizing the number of base-station antennas, which are increasing rapidly.
\end{abstract}

\section{Introduction}

Modern mobile communication networks are expected to accommodate both current and legacy communications standards. This inevitably involves the provision of radio coverage in a number of frequency bands and complicates the design of the network base transceiver stations (BTS). With respect to antennas, the expense of multiple base-station antenna installations and public resistance to unsightly antenna placements has motivated the installation of multiband antennas at base-stations and thus avoids an increase of antenna masts and payloads. Multiband antennas are usually expected to demonstrate comparable performance measures (especially input impedance, radiation pattern, and polarization) in each of their operating bands and have been the subject of vigorous research over the past two decades [1].

Significant advances have been made in designing antennas with sufficient bandwidth in two or even three different bands using multiresonance and operating band reconfigurable techniques [2-14]. For the most part, this research has been concerned with the design of isolated multiband elements, and relatively little work has been done to address the problems inherent in multiband array design $[15,16]$. In particular, the element geometry and layout of multiband arrays must be carefully chosen to avoid the appearance of grating lobes in the radiation pattern. Basestation antenna arrays present further challenges in that they require shaped radiation patterns to limit intersite interference and must satisfy very low intermodulation limits [1].

Most studies on multiband antennas, however, have thus far focused on applications for mobile terminals that can be operated at low power. For the base-station, multiband antennas mainly have been researched by antenna manufacturers, and recently some major antenna manufacturers have introduced triple-band models. As the number of services increases, many additional base-station antennas and infrastructure should be installed for new services. In addition 
TABLE 1: Operating bands of the multiband base-station antenna.

\begin{tabular}{lcc}
\hline $\begin{array}{l}\text { Operating } \\
\text { band }\end{array}$ & Frequency band $[\mathrm{GHz}]$ & Service \\
\hline Band 1 & TX: $0.869 \sim 0.894$ & Cellular \\
\hline Band 2 & RX: $0.824 \sim 0.849$ & PCS, WCDMA, \\
\hline Band 3 $2.110 \sim 2.170$ & WiMax, WiFi \\
\hline RX: $1.920 \sim 1.980$ & WiBro, WiMax \\
\hline
\end{tabular}

to rising costs for the installation and maintenance of the new service infrastructure, problems such as harmful effects on the human body by radiating power from antennas and despoiled city landscapes have been noted. Multiband antennas that provide more services than do existing antenna models are thus being highly recommended by service providers and governments. It has been shown in [17] that multiband antennas do not require larger compliance distances than the worst-case single band antenna with the same total output power. Thus ETRI (Electronics and Telecommunications Research Institute) of South Korea has also researched on the multiband base-station antenna to settle the problems mentioned above. It proposed a switchable quad-band antenna which is composed of four printed dipoles operating in $0.8 \sim 5.9 \mathrm{GHz}$ [18]. But the antenna cannot provide dualpolarization characteristic for polarization diversity and the array size using the proposed structure is large. Thus we want to develop a multiband base-station antenna satisfying the commercial requirements.

The multiband antenna introduced in this paper can provide more than five services simultaneously in a frequency range of $0.8 \sim 6.0 \mathrm{GHz}$. For example, there are many mobile services in Korea such as cellular, PCS (personal communication services), WCDMA (wideband code division multiple access), WiBro (wireless broadband Internet), LTE (Long-Term Evolution), and WiFi (wireless fidelity), and the proposed antenna can provide all existing services. Although the new frequency band of the LTE service ( $1.8 \mathrm{GHz}$ band) is not distributed for service providers, the proposed antenna can provide it by revising the antenna operating frequency. This antenna has a shared aperture, having several array antenna sets for multiple services. Table 1 shows the antenna operating bands and their services. In this table, the LTE is not shown due to its undetermined operating frequency.

\section{Element Antenna Design}

In this base-station antenna design, four individual element antennas are required to realize optimal performance for each operating band in a high radiating power environment. They are shown in Figure 1. Band 1 radiator is composed of four bended dipoles with a rectangular shape slanted by $45^{\circ}$. In this structure, each pair of dipoles facing each other is designed to have equal phase and amplitude. Thus they can radiate a signal with $+45^{\circ}$ linear polarization (port 1 ) and $-45^{\circ}$ linear polarization (port 2). The edges of all dipoles are bent to minimize the radiator size, which is very advantageous in the design of an array antenna arranged in the vertical or horizontal plane [19]. Band 2 and Band 3 radiators are composed of four folded dipoles with a rectangular shape, similar to Band 1 radiator. But these radiators are designed with a planar commercial substrate, named FR-4 $\left(\varepsilon_{r}=4.4, t=\right.$ $1.5 \mathrm{~mm}$ ). In the structure of Band 2, two radiators facing each other at the top side of the substrate operate with $+45^{\circ}$ linear polarization (port 1), and the other two radiators are designed at the bottom side to operate with $-45^{\circ}$ linear polarization (port 2). The radiators at the bottom side are depicted by a dotted line and have the same dimensions as the radiators at the top side. Using this structure, the dipole radiators in both sides are not overlapped and we can realize size reduction of the radiator. Band 3 radiator has a similar structure to Band 2 radiator, but all dipoles are constructed at the top side of the substrate. The modified folded dipole at the edge is used to minimize the dipole length. Band 3 radiator can also be operated with $\pm 45^{\circ}$ linear polarization $\left(+45^{\circ}\right.$ for port 2 and $-45^{\circ}$ for port 1) and fabricated with a FR-4 substrate [20]. Band 4 radiator has a stacked planar microstrip structure. The stacked structure is used to obtain a wideband characteristic. The main patch and the feed line are designed with a TLY-5A substrate $\left(\varepsilon_{r}=2.17, t=0.508 \mathrm{~mm}\right)$, and the parasitic patch is fabricated with alumina $(t=1.0 \mathrm{~mm})$. The parasitic patch is fixed with a cylindrical supporter in the center of the main patch. For $+45^{\circ}$ linear polarization, a dual feeding structure is used $\left(+45^{\circ}\right.$ for port 2 and $-45^{\circ}$ for port 1$)$.

Besides electrical performances, the antenna size is very important for fabrication cost and the installation in limited space such as a tower and the roof of a building in the multiband base-station antenna design. Thus we used the dual band radiators which are composed of the single band radiators shown in Figure 1 to take up the small space as much as Band 1 radiator only. The structure of the dual band radiators is depicted in Figure 2. Figure 2(a) is for Band 1 and Band 2, and Figure 2(b) is for Band 1 and Band 3. Band 1 radiator is much larger than Band 2 and Band 3 radiators, and thus small radiators (Band 2 and Band 3 radiator) can be placed in the center of Band 1 radiator without any performance degradation. Using these structures, we can realize a multiband array antenna. Band 4 radiator is not composed of other considered radiators. The frequency of Band 4 is relatively high compared with other operating bands and the array spacing for Band 4 is not suitable for other band radiators. The main design parameters are summarized in Table 2.

The simulation results of the radiators are shown in Figures 3 and 4. From Figure 3, it can be seen that all radiators have good reflection coefficient $\left(S_{11}\right.$ and $\left.S_{22}\right)$ below $-13 \mathrm{~dB}$ for all ports and the port isolation $\left(S_{21}\right)$ above $19.6 \mathrm{~dB}$. Figure 4 shows the simulated radiation patterns of $E$-plane for all radiators. The radiators of Band 1 and Band 4 have almost the same radiation patterns for all ports because the radiator structures for each of the ports are exactly symmetrical, but the radiators of Band 2 and Band 3 have slightly different patterns shape for the ports. The gains of the single radiators 
TABLE 2: Main design parameters of element antennas [unit: $\mathrm{mm}$ ].

\begin{tabular}{lccccccccccc}
\hline Mark & Value & Mark & Value & Mark & Value & Mark & Value & Mark & Value & Mark & Value \\
\hline S1 & 160.5 & L1 & 109.5 & W1 & 21 & D1 & 173.7 & T1 & 1.5 & H1 & 60 \\
S2 & 68 & L2 & 43 & W2 & 5.8 & D2 & 87 & T2 & 1.5 & H2 & 39 \\
S3 & 59 & L3 & 42 & W3 & 6 & D3 & 72 & T3 & 1.5 & H3 & 36.5 \\
& & L4 & 22 & & & D4 & 31.1 & T4 & 1.0 & H4 & 4.5 \\
& & L5 & 16 & & & D5 & 22.6 & T5 & 0.508 & & \\
\hline
\end{tabular}

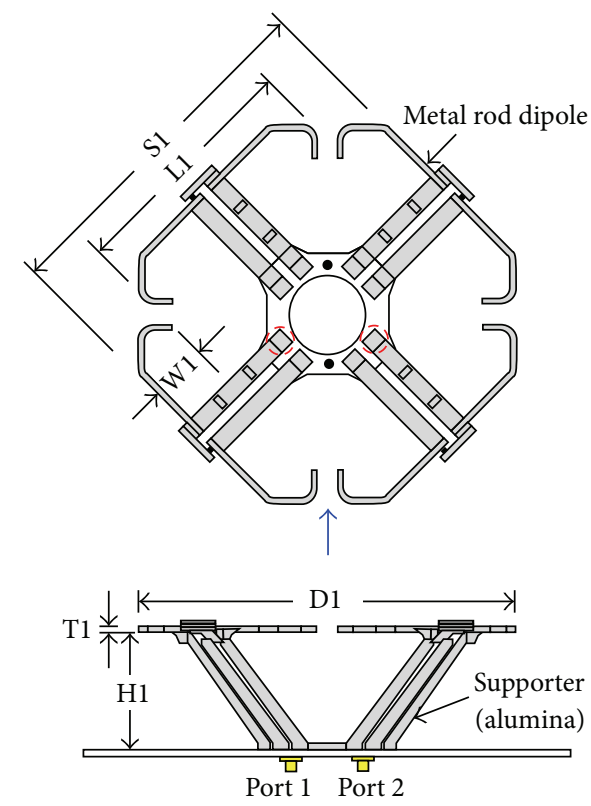

(a)
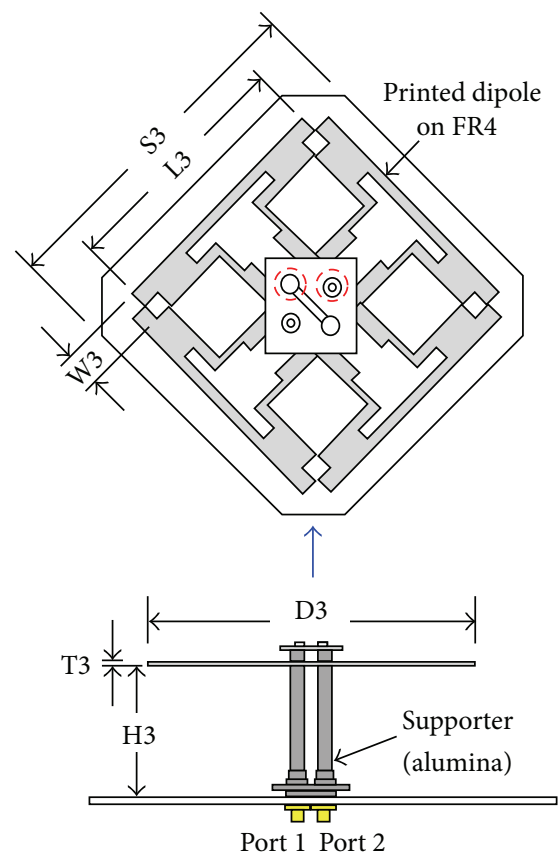

(c)

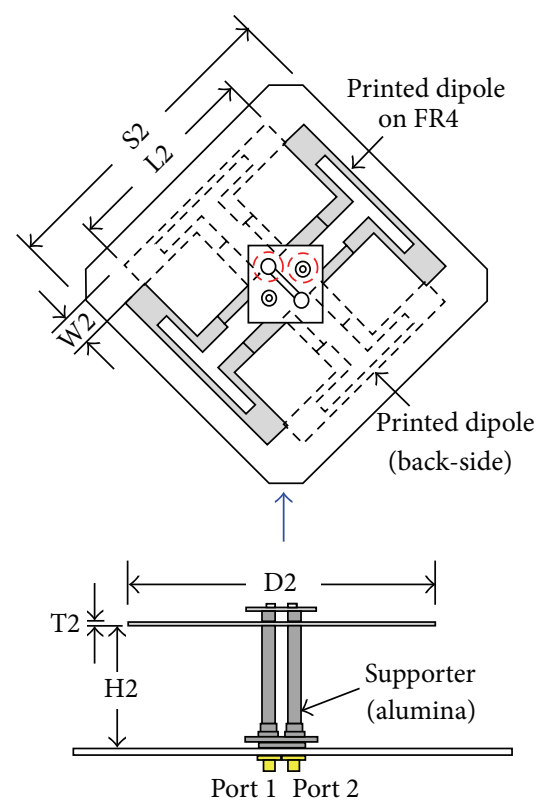

(b)
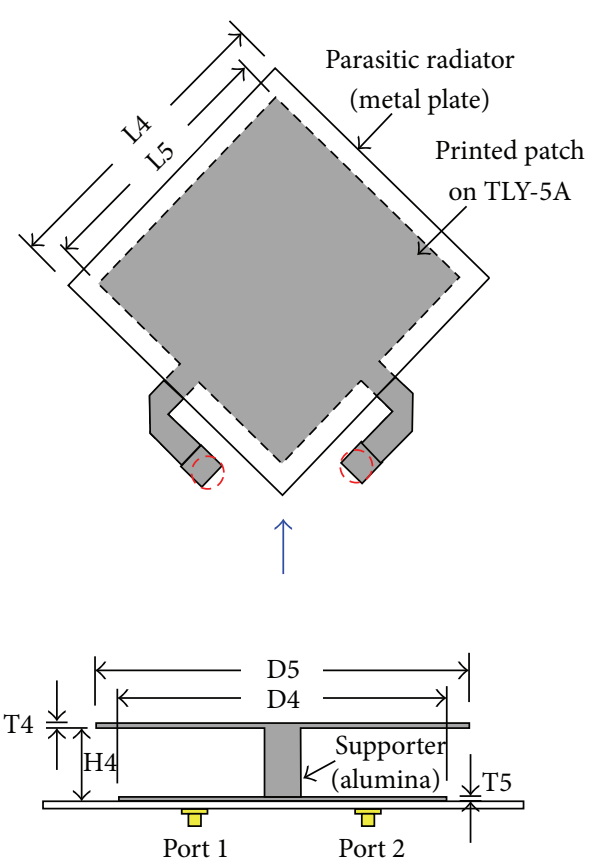

(d)

FIGURE 1: Single band radiator structure: (a) Band 1, (b) Band 2, (c) Band 3, and (d) Band 4 (up: top view, down: side view, and large arrow: direction of side view). 


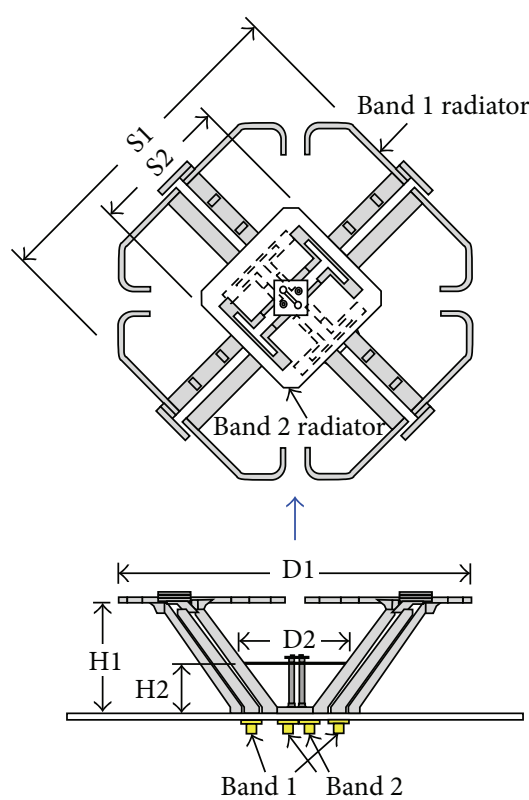

(a)

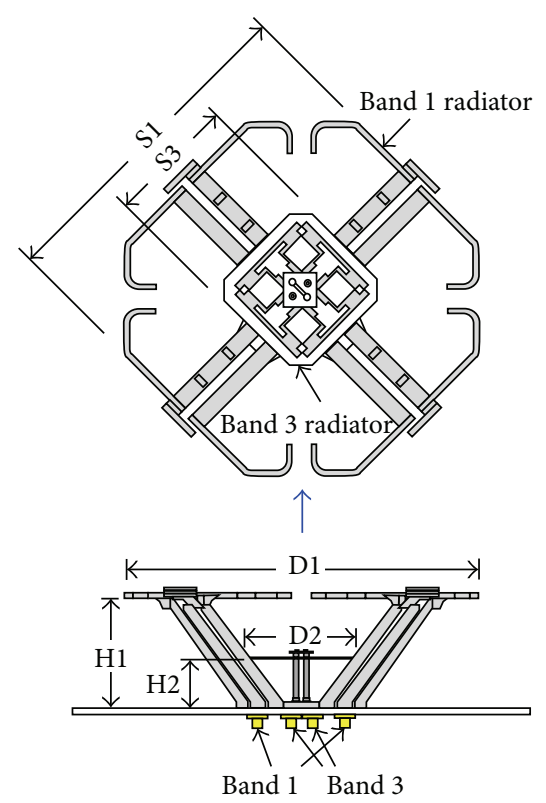

(b)

Figure 2: Dual band radiator structure: (a) Band $1+$ Band 2; (b) Band $1+$ Band 3 (up: top view, down: side view, and large arrow: direction of side view).

are $7.1 \mathrm{dBi}, 6.4 \mathrm{dBi}, 6.2 \mathrm{dBi}$, and $6.7 \mathrm{dBi}$ for Band 1, Band 2, Band 3, and Band 4, respectively.

\section{Multiband Array Antenna Design}

In the multiband array antenna design, it is imperative that all the arrays from Band 1 to Band 4 provide optimal performance without electrical and mechanical interference with each other. We thus deliberated on array structures using single band and dual band radiators and analyzed the array spacing for all bands. As mentioned above, the frequency of Band 1 is the lowest of the studied operating bands, while Band 2 and Band 3 have similar frequencies separated by only $210 \mathrm{MHz}$. Band 4 has a high frequency compared with the other bands. Taking into consideration the wavelength of all bands at the center frequency, we can arrange all arrays to comprise 8 elements, as shown in the top half of Figure 5:

Band 1: $(\mathrm{TX})$ center frequency $=0.881 \mathrm{GHz}\left(\lambda_{0}=\right.$ $340.3 \mathrm{~mm})$,

(RX) center frequency $=0.837 \mathrm{GHz}\left(\lambda_{0}=358.6 \mathrm{~mm}\right)$;

Band 2: $(\mathrm{TX})$ center frequency $=2.140 \mathrm{GHz}\left(\lambda_{0}=\right.$ $140.2 \mathrm{~mm})$,

$(\mathrm{RX})$ center frequency $=1.950 \mathrm{GHz}\left(\lambda_{0}=153.8 \mathrm{~mm}\right)$;

Band 3: $(\mathrm{TX})$ center frequency $=2.350 \mathrm{GHz}\left(\lambda_{0}=\right.$ $127.7 \mathrm{~mm}$ ),

$(\mathrm{RX})$ center frequency $=2.350 \mathrm{GHz}\left(\lambda_{0}=127.7 \mathrm{~mm}\right)$;

Band 4: $(\mathrm{TX})$ center frequency $=5.500 \mathrm{GHz}\left(\lambda_{0}=\right.$ $54.5 \mathrm{~mm})$,

$(\mathrm{RX})$ center frequency $=5.500 \mathrm{GHz}\left(\lambda_{0}=54.5 \mathrm{~mm}\right)$.

For grating lobe suppression, we want to design all arrays with minimum array spacing below $1.0 \lambda_{0}$ [21]. First, we designed Band 1 array with array spacing from $0.70 \lambda_{0}$ to $1.0 \lambda_{0}$ considering the radiator size. To minimize the entire antenna size, it is very helpful to use multiband radiators, as depicted in Figure 2, for space sharing. We used eight dual band radiators at both sides of the multiband array, and four of these radiators are for "Band $1+$ Band 2 " and the others are for "Band $1+$ Band 3." In addition, four single band radiators for "Band 2 and Band 3" are placed between the dual band radiators, as shown in the lower diagram of Figure 5. Thus we could realize a composite array structure with three individual radiators. In Figure 5, Band 2 array is placed in the left half of the multiband array structure, and Band 3 array is in the right half of the structure. Using this configuration, we can realize a triple-band array antenna within the size of a single band array for Band 1 . Band 4 radiator is much smaller than the other radiators and the array spacing is very close in the aspect of electrical wavelength. If Band 4 array is designed with other radiators, interference with other large radiators is possible, which can block the radiation of Band 4 radiator. Band 4 array was thus designed separately from the other band arrays:

$$
\begin{aligned}
& \text { Band 1: spacing }=250 \mathrm{~mm}\left(\mathrm{TX}: 0.73 \lambda_{0}, \mathrm{RX}: 0.70 \lambda_{0}\right) \\
& \text { Band 2: spacing }=125 \mathrm{~mm}\left(\mathrm{TX}: 0.90 \lambda_{0}, \mathrm{RX}: 0.81 \lambda_{0}\right) ; \\
& \text { Band 3: spacing }=125 \mathrm{~mm}\left(\mathrm{TX}: 0.98 \lambda_{0}, \mathrm{RX}: 0.98 \lambda_{0}\right) \\
& \text { Band 4: spacing }=42.5 \mathrm{~mm}\left(\mathrm{TX}: 0.78 \lambda_{0}, \mathrm{RX}: 0.78 \lambda_{0}\right)
\end{aligned}
$$

For the array of "Band 2 and Band 3," the final array spacing is $125 \mathrm{~mm}$, which was decided by a performance analysis according to the array spacing. The array spacing exceeding $125 \mathrm{~mm}$ makes SLL (Side-Lobe Level) of Band 3 array degraded by a grating lobe, while the spacing below $125 \mathrm{~mm}$ makes the interference among the radiators increase. The array spacing of $125 \mathrm{~mm}$ is $0.90 \lambda_{0}$ for TX and $0.81 \lambda_{0}$ for 


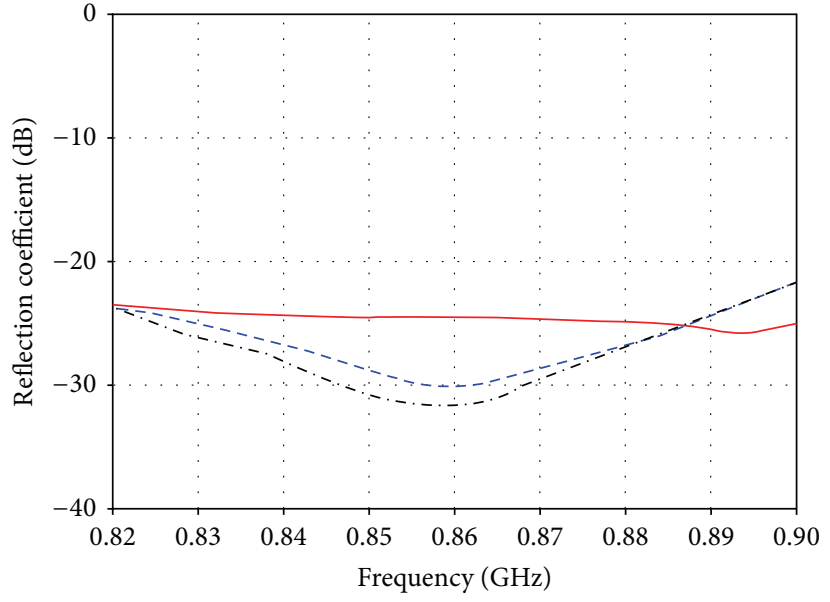

(a)

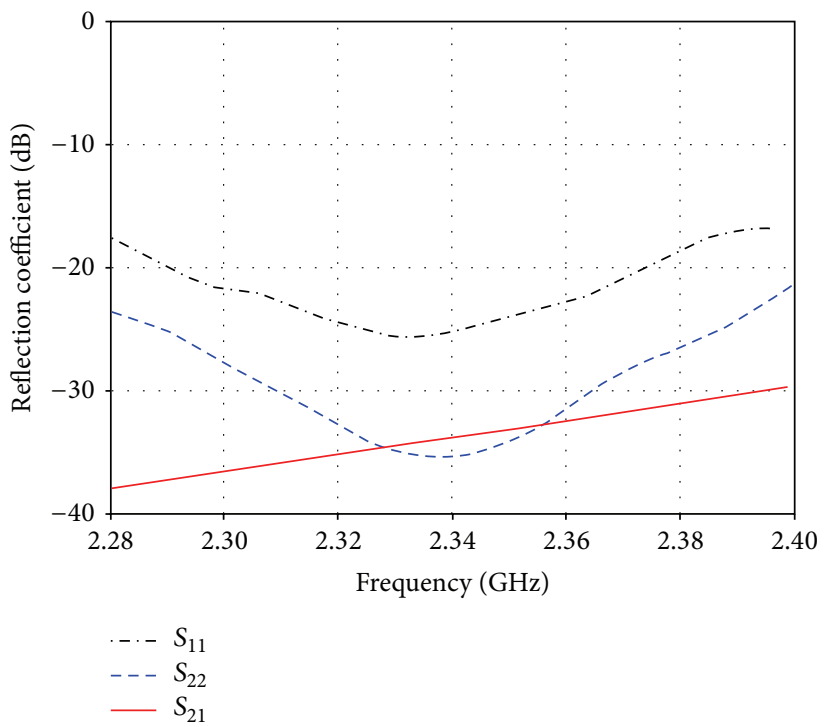

(c)

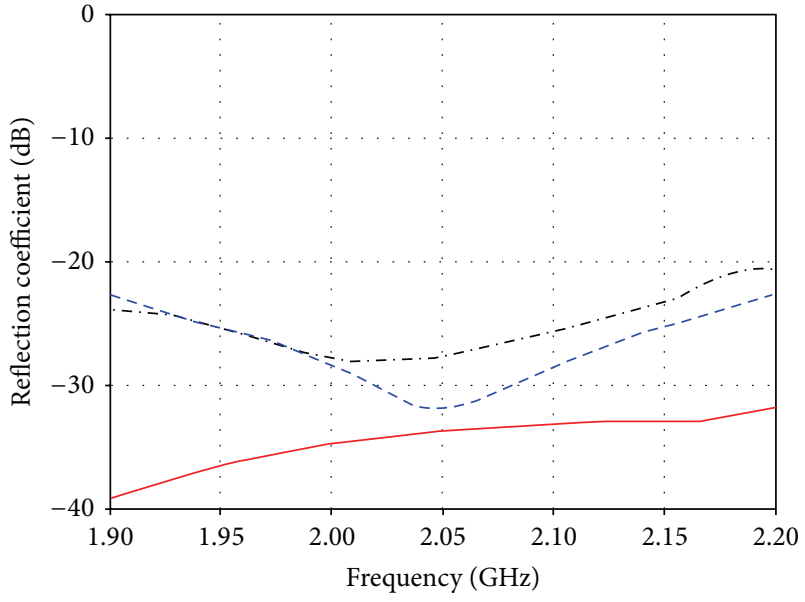

(b)

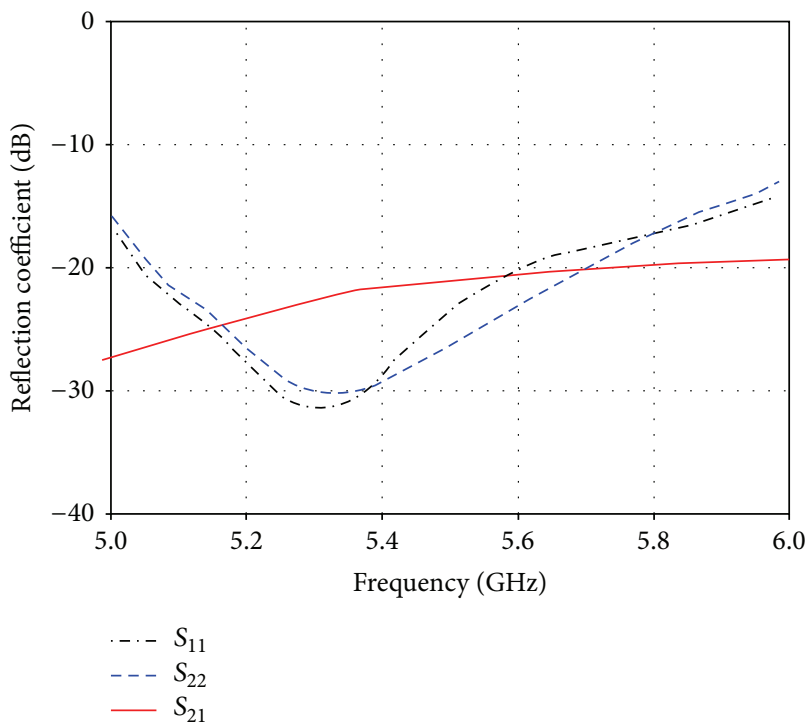

(d)

FIGURE 3: Simulated reflection coefficient and isolation characteristic of the radiators: (a) Band 1, (b) Band 2, (c) Band 3, and (d) Band 4.

$\mathrm{RX}$, and the spacing for Band 3 is $0.98 \lambda_{0}$ for TX and RX. Thus Band 1 array is designed with array spacing of $250 \mathrm{~mm}\left(0.73 \lambda_{0}\right.$ for TX and $0.70 \lambda_{0}$ for RX). Band 4 array is designed with array spacing of $42.5 \mathrm{~mm}$, which is $0.78 \lambda_{0}$ for TX and RX.

\section{Fabrication and Performance Test}

Figure 6 shows the photo of the fabricated multiband antenna having the array antenna design concept depicted in Figure 5 and the photos of the fabricated radiators used in the multiband array antenna are shown in Figure 7. Figures 7(a) and $7(\mathrm{~b})$ present the dual band radiators shown in Figure 6. The dipoles of Band 1 radiator are fabricated with a metal rod having a radius of $2 \mathrm{~mm}$, and we combined the dipoles with alumina supporters using screws. Finally, assembled Band 1 radiator is fixed in an antenna ground plane with screws, and $\mathrm{RF}$ cables are directly connected to the feeding point at the bottom side of the radiator. The feeding points are marked with bold dashed circles in the top views of Figure 1. For Band 2 and Band 3 radiators, an alumina supporter is first fixed in the ground plane using screws and the printed dipoles are connected on the top side of the supporter. RF cables are connected to the feeding point at the bottom side of the radiators also. Figure 7(c) shows fabricated Band 4 radiator. The square patch shown in this photo is the alumina parasitic radiator and the main square patch which is designed with a commercial substrate is situated under the parasitic patch. The main patch is fixed in the ground plane, and a parasitic patch having a cylindrical supporter is assembled at the center of the main patch with a long screw.

A performance test of the fabricated antenna was performed. First, the return loss and isolation characteristics were tested. The isolation characteristics are especially important because all radiators can provide dual-polarization of $\pm 45^{\circ}$ using dual-ports and we can realize the other linear and circular polarizations by using the phase control circuit in 


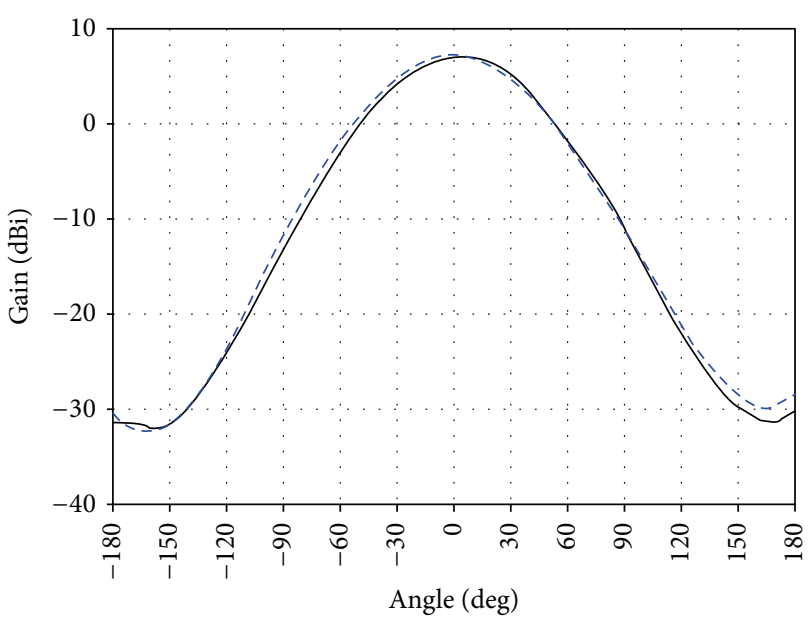

(a)

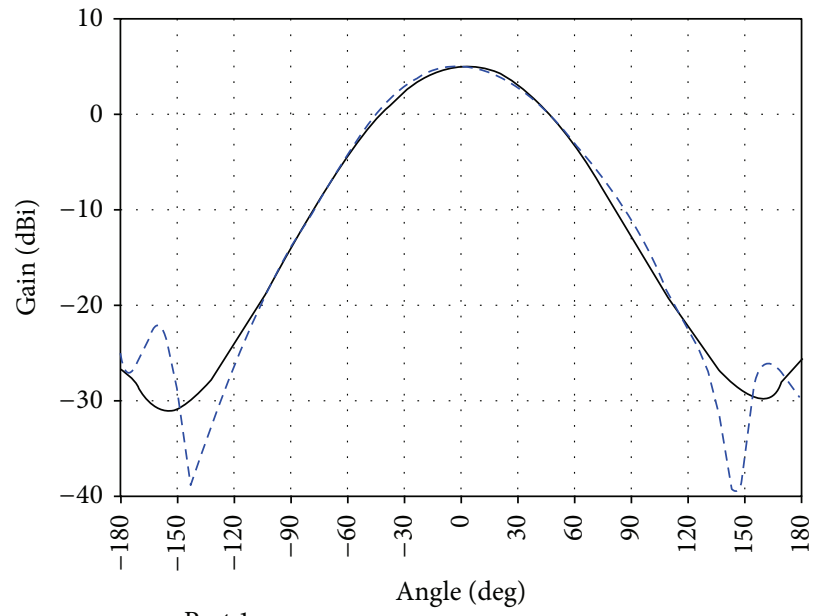

- Port 1

- - - Port 2

(c)

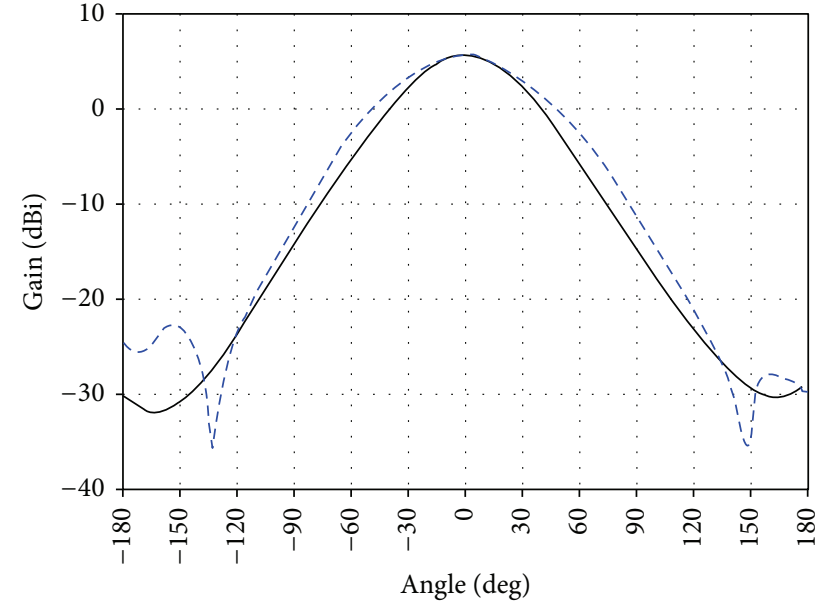

(b)

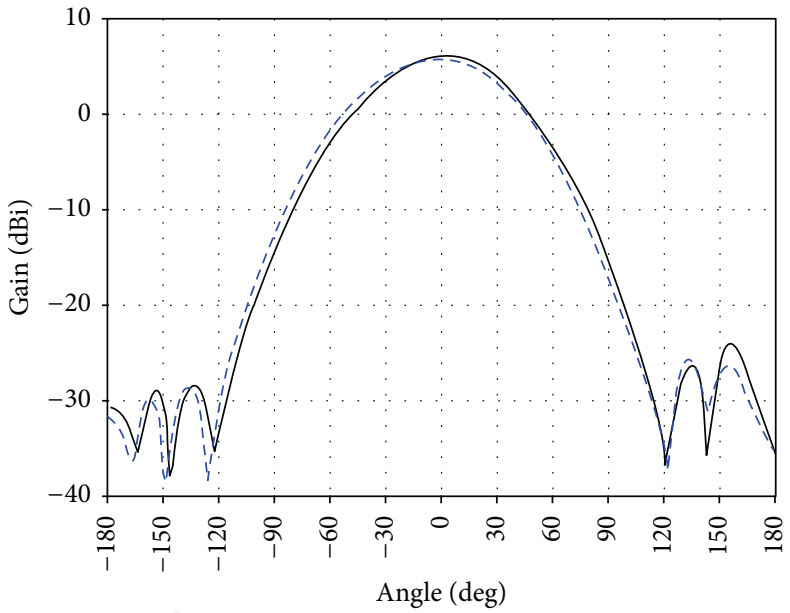

- Port 1

- - Port 2

(d)

FIGURE 4: Simulated radiation patterns of the radiators of $E$-plane: (a) $0.881 \mathrm{GHz}$ for Band 1, (b) $2.14 \mathrm{GHz}$ for Band 2, (c) $2.35 \mathrm{GHz}$ for Band 3 , and (d) $5.5 \mathrm{GHz}$ for Band 4 .

the feed network. All measured results for the arrays of each band are shown in Figure 8. Band 1 array has return loss $\left(S_{11}\right.$ and $\left.S_{22}\right)$ below $-20 \mathrm{~dB}$ for all ports and the isolation $\left(S_{21}\right)$ between the ports is below $-18.5 \mathrm{~dB}$ from 0.824 to $0.894 \mathrm{GHz}$. The measured frequency includes both TX and RX bands. Band 2 array has return loss below $-19.5 \mathrm{~dB}$ for all ports and the isolation is below $-32 \mathrm{~dB}$ from 1.92 to $2.17 \mathrm{GHz}$. For Band 3 array, the minimum return loss and isolation are $-20 \mathrm{~dB}$ and $-33 \mathrm{~dB}$, respectively, for an operating band from 2.30 to $2.40 \mathrm{GHz}$. Band 4 array has return loss below $-10.2 \mathrm{~dB}$ and isolation below $-14.5 \mathrm{~dB}$. Because Band 4 radiator has a dual-port per single radiator, it is relatively more sensitive than the single feeding structure in terms of its return loss and isolation characteristics. A radiation pattern test of the fabricated antenna was performed in a compact range chamber and far-field range anechoic chamber of Orbit Inc. with the cooperation of ACE Technology Inc. All measured radiation patterns are depicted in Figure 9. The radiation patterns measured at the center frequency of the TX and RX bands for Band 1 and Band 2 are shown from Figures 9(a)9(d). The radiation patterns of Band 3 and Band 4 are shown from Figures 9(e)-9(h) at the start and the center frequency because the TX and RX operating frequency are the same. From the results at the center frequencies, Band 1 array has the gain of $17.4 \mathrm{dBi}$ and $17.1 \mathrm{dBi}$ for the cross-polarization characteristic of $24.5 \mathrm{~dB}$ and $25.0 \mathrm{~dB}$ with SLL of $12.5 \mathrm{~dB}$ and $12.6 \mathrm{~dB}$, for RX and TX, respectively. The gain of Band 2 array is $17.2 \mathrm{dBi}$ for TX and $16.6 \mathrm{dBi}$ for RX. The SLL is $12.2 \mathrm{~dB}$ and $13.7 \mathrm{~dB}$ and the cross-polarization characteristic is $26.8 \mathrm{~dB}$ and $27.2 \mathrm{~dB}$, for RX and TX, respectively. For Band 3 array, the minimum gain is 16.6 , the SLL is $11.6 \mathrm{~dB}$, and the crosspolarization is $32.5 \mathrm{~dB}$. Band 4 has a gain of $14.0 \mathrm{dBi}$ with a SLL of about $11.8 \mathrm{~dB}$.

The minimum value of cross-polarization is $15.0 \mathrm{~dB}$. As mentioned above, Band 4 radiator has a common patch structure with dual-ports having inherent sensitive port isolation, 


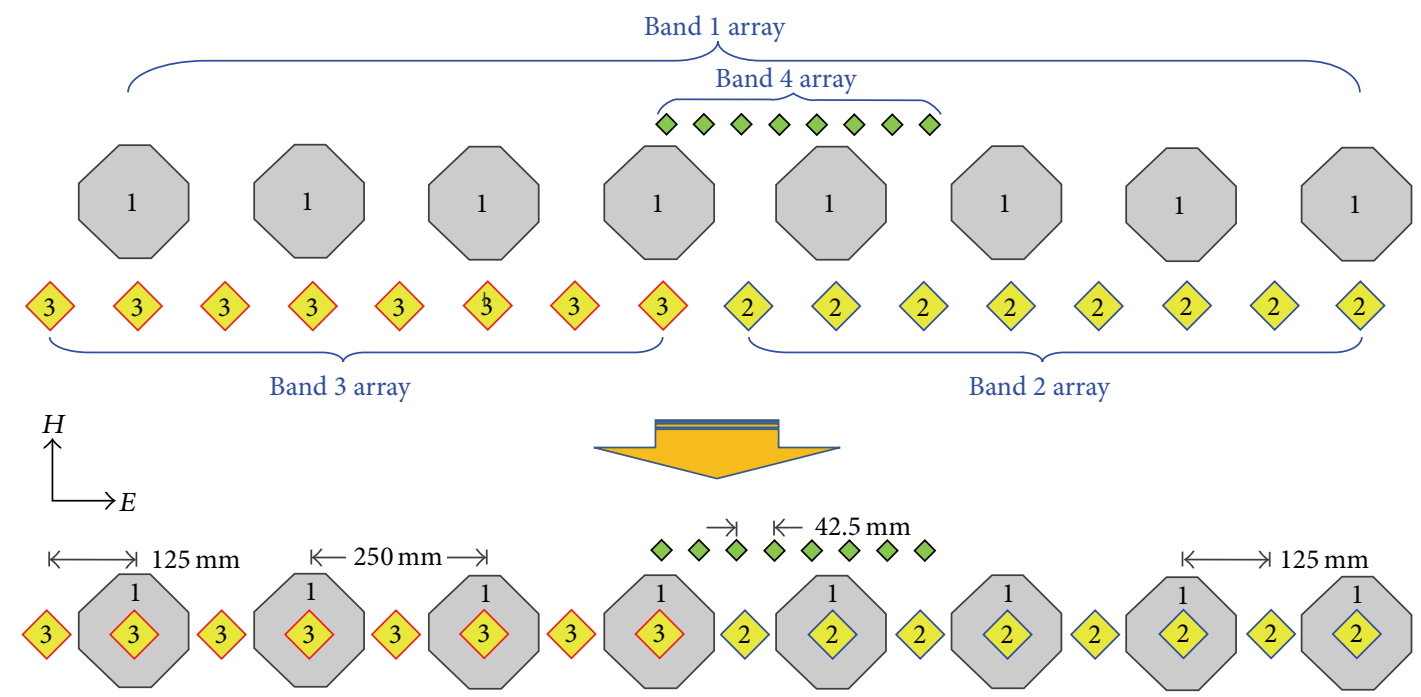

FiguRE 5: Multiband array design concept for optimal performance and size reduction (1: Band 1 radiator, 2: Band 2 radiator, 3: Band 3 radiator, and 4 : Band 4 radiator).

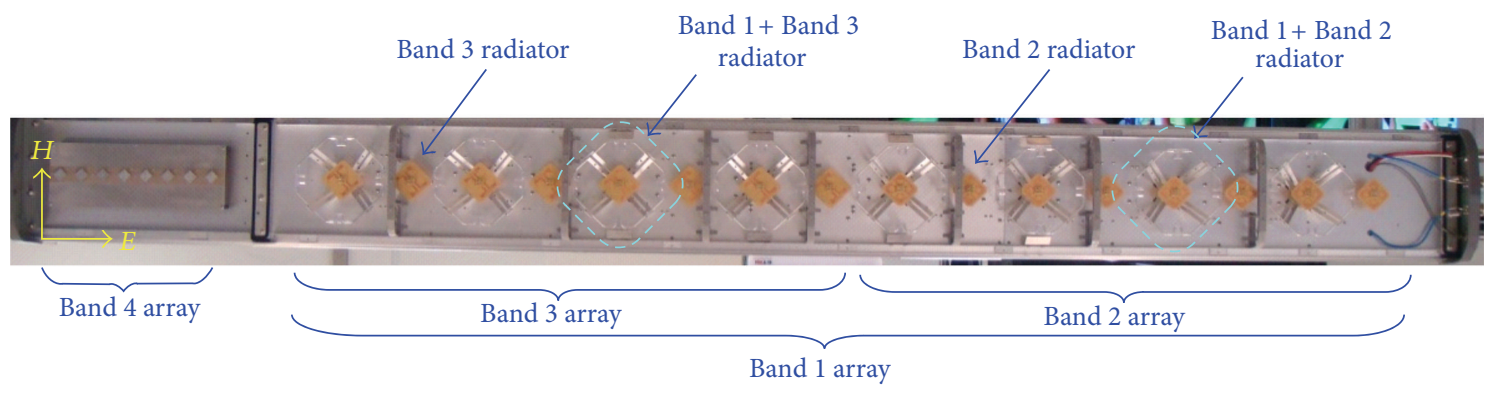

FIGURE 6: Fabricated multiband array antenna.

and thus the cross-polarization characteristic is not good compared with other arrays. The $3 \mathrm{~dB}$ beamwidth of all arrays ranged from $4.9^{\circ}$ to $7.8^{\circ}$ for elevation and $45.2^{\circ}$ to $71.1^{\circ}$ for the azimuth direction, satisfying the requirements for sector antenna applications for base-stations. The coordination for the measurement direction is provided in Figure 6.

The F/B (front-to-back) ratio, which is the ratio of power gain between the front and rear of a directional antenna, is above $30.0 \mathrm{~dB}$ for all arrays. The minimum measured performances of the proposed antenna for each operating band are summarized in Table 3. As seen in the table, the proposed antenna has wide operating bandwidth from 0.824 to $5.850 \mathrm{GHz}$ and the proposed antenna has the small size of $2480 \mathrm{~mm} \times 220 \mathrm{~mm} \times 95 \mathrm{~mm}$. The size reduction can be realized by the proposed array structure using the dual band radiators. The weight of the proposed antenna is $28.5 \mathrm{Kg}$ including a fiberglass radome.

\section{Conclusion}

In this paper, we proposed a multiband array antenna with dual-polarization. This antenna can provide multiple mobile services in four frequency bands from 0.8 to $6 \mathrm{GHz}$. This antenna is composed of four individual arrays having two ports for $\pm 45^{\circ}$ linear polarization and can provide mobile services such as cellular, PCS, WCDMA, WiBro, WiMax, LTE, and WiFi independently or simultaneously. In the multiband array antenna design, we deliberated on array structures using single band and dual band radiators (Band $1+$ Band 2 and Band $1+$ Band 3 ) for optimal performance of all the arrays from Band 1 to Band 4 without electrical and mechanical interference with each other.

Using the proposed array structure, we can realize fourband base-station antenna having good performances which come close to commercial single band base-station antennas, and the size and the weight of the antenna can be considerably reduced compared with the commercial models.

We are now developing a multiband active base-station antenna using the proposed array structure in this paper which can electrically control the antenna beams for next generation mobile communications.

\section{Conflict of Interests}

The authors declare that there is no conflict of interests regarding the publication of this paper. 


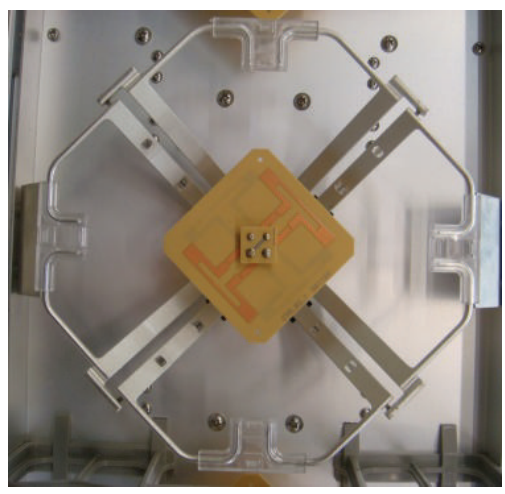

(a)

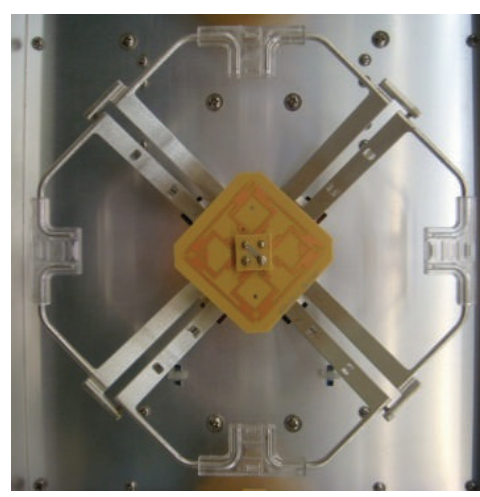

(b)

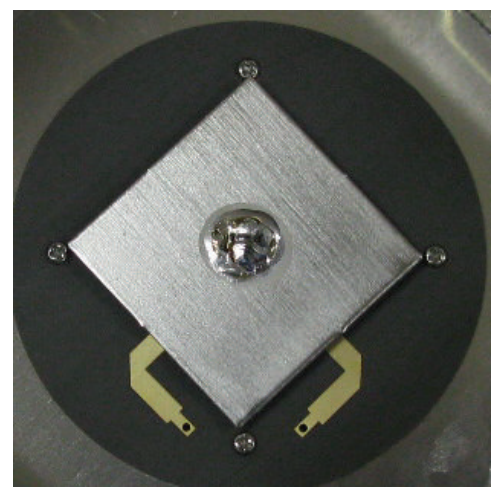

(c)

Figure 7: Top view of fabricated radiators for multiband base-station antenna: (a) Band 1+ Band 2, (b) Band 1+ Band 3, and (c) Band 4.

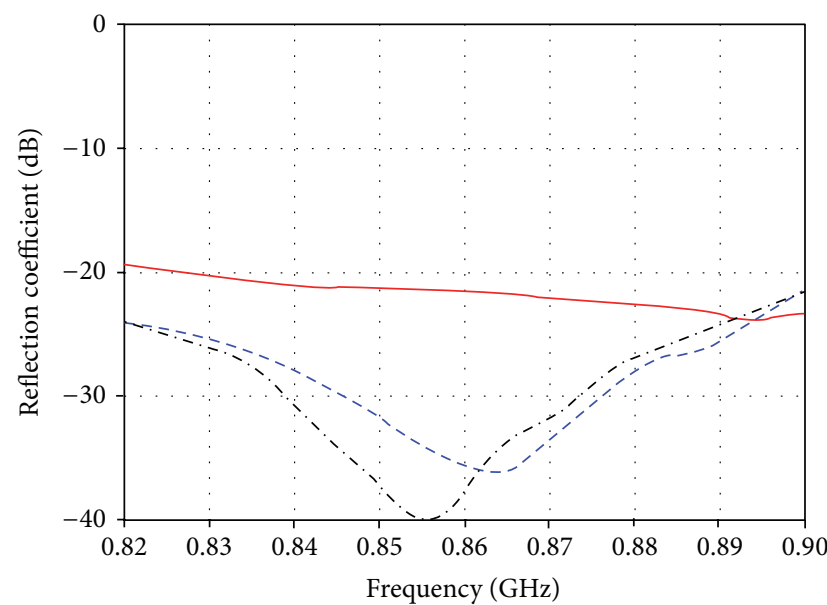

(a)

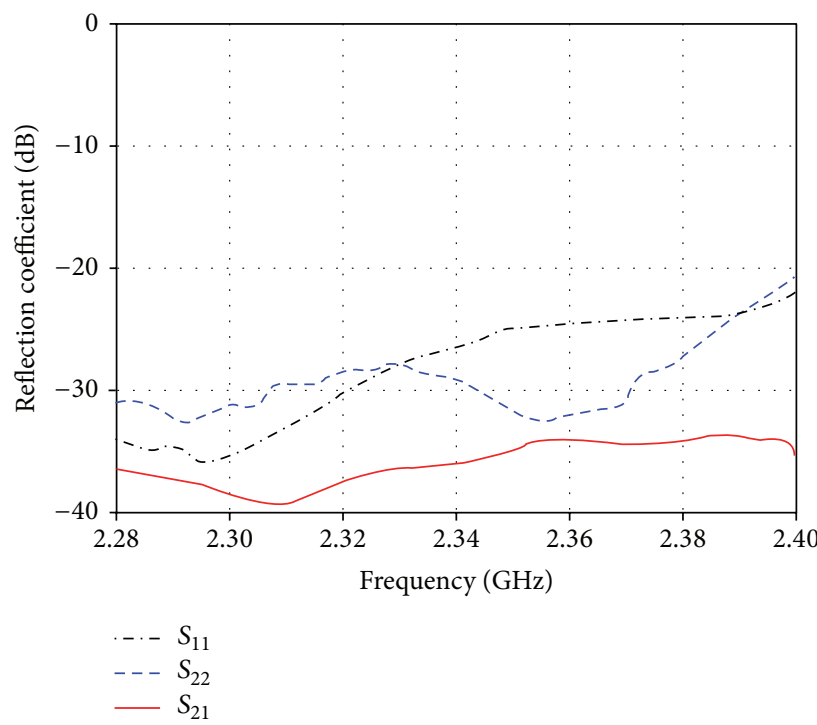

(c)

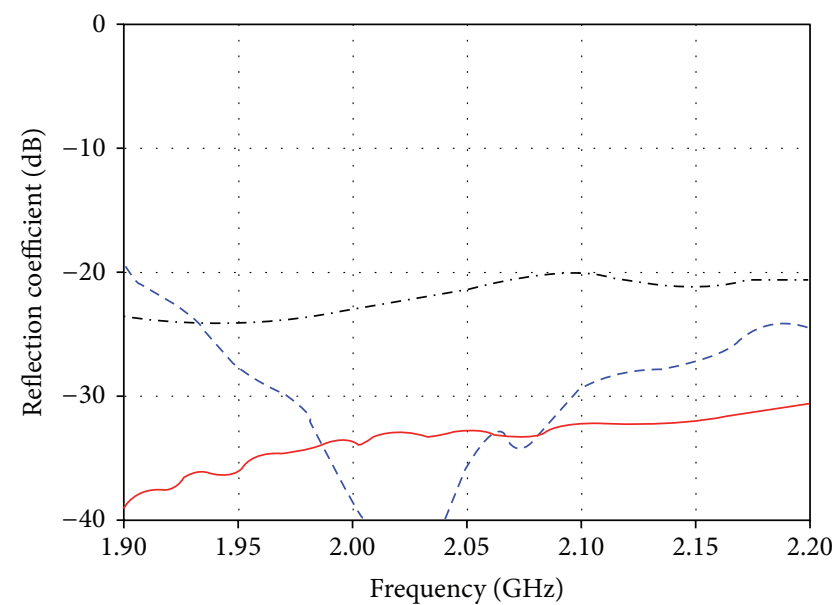

(b)

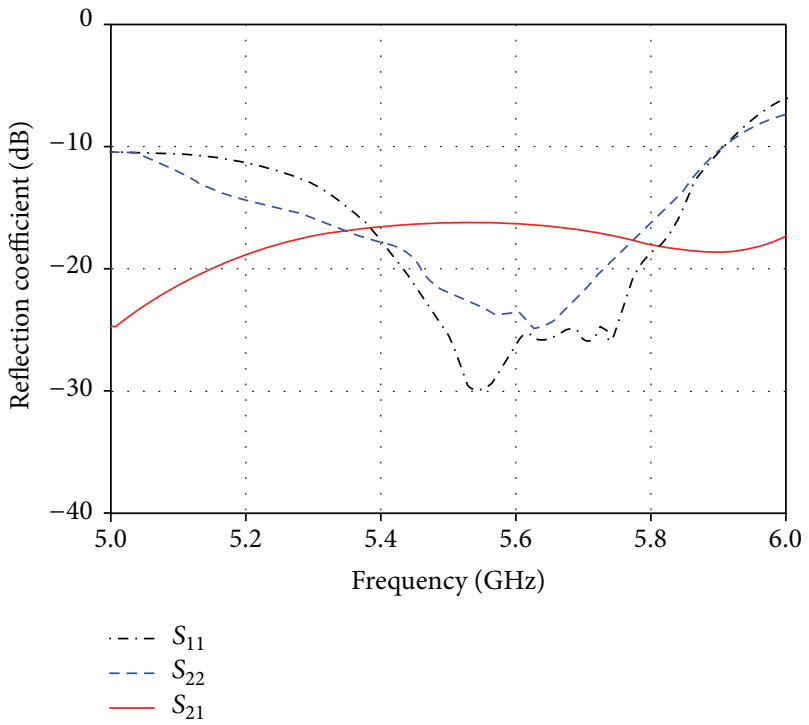

(d)

FIgURE 8: Measured return loss and isolation characteristic of the multiband array: (a) Band 1, (b) Band 2, (c) Band 3, and (d) Band 4. 


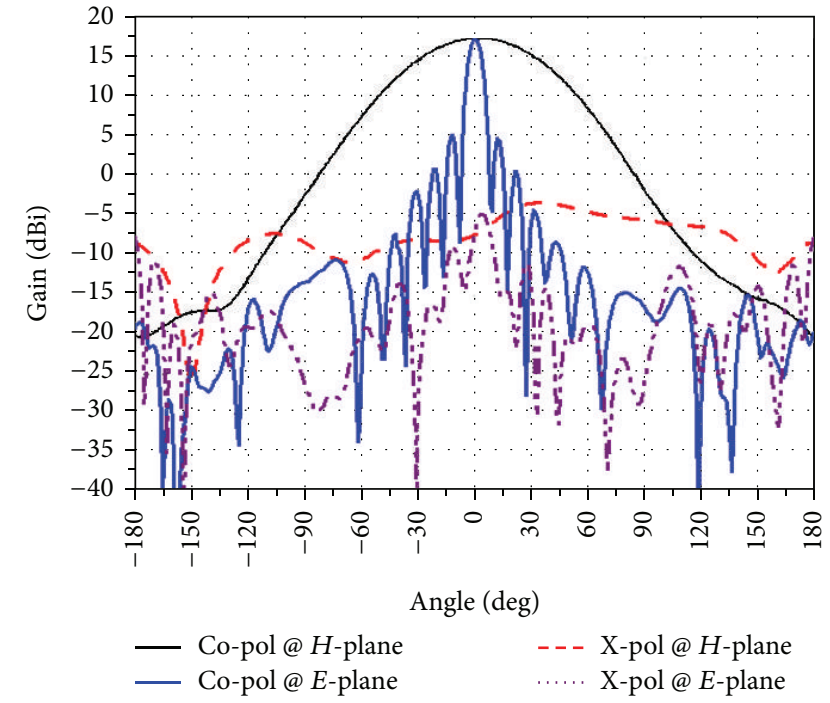

(a)

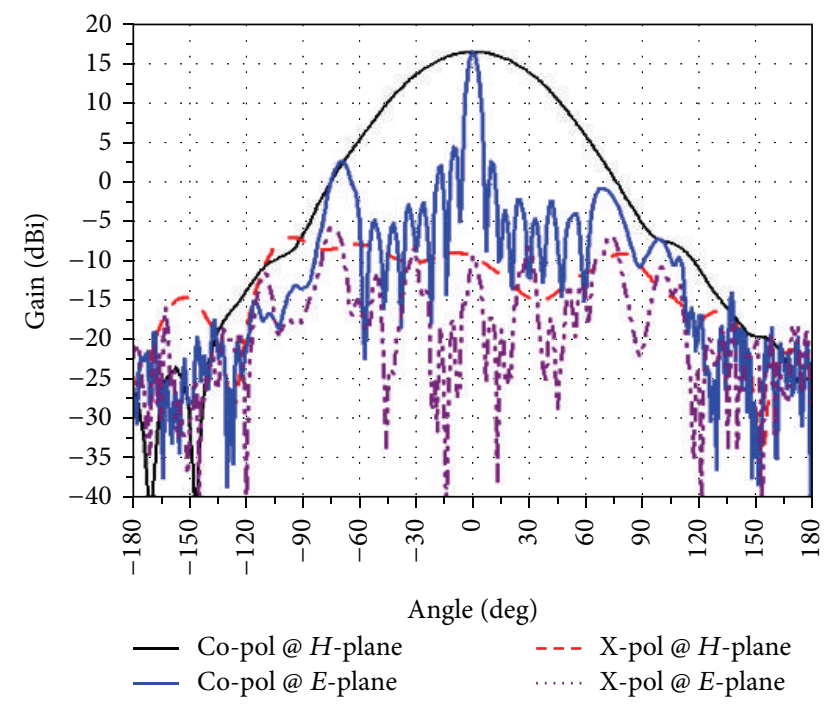

(c)

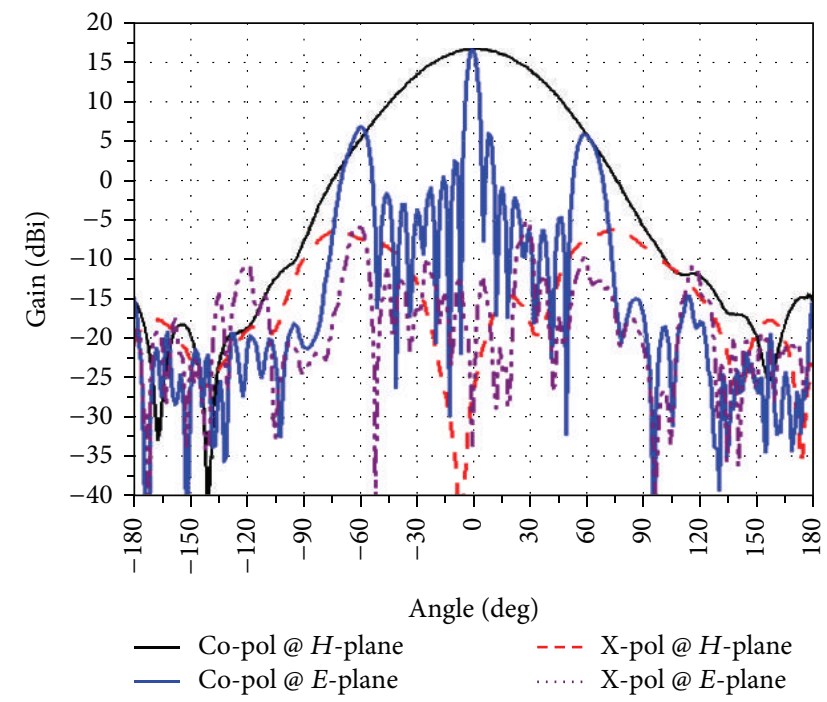

(e)

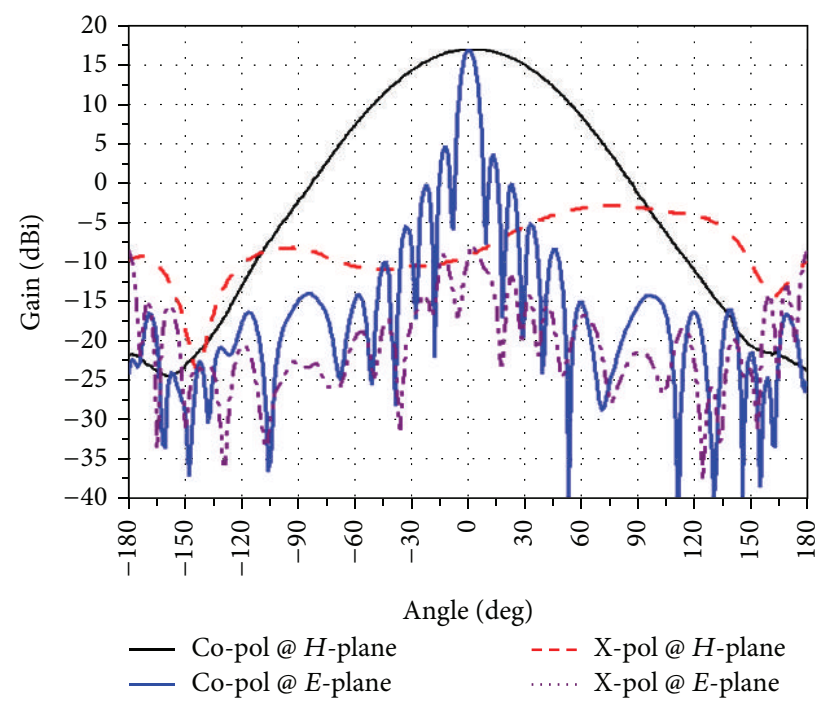

(b)

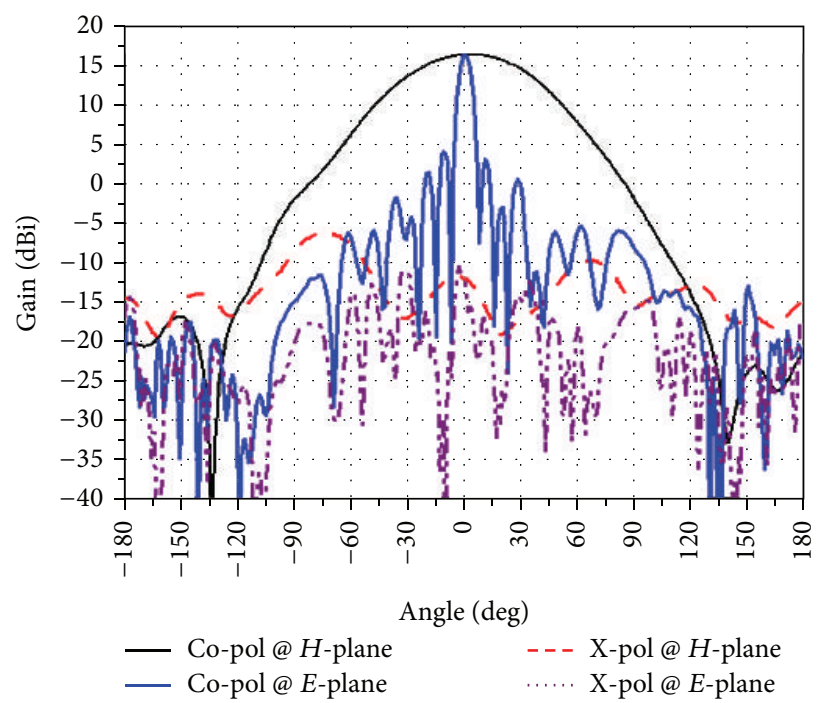

(d)

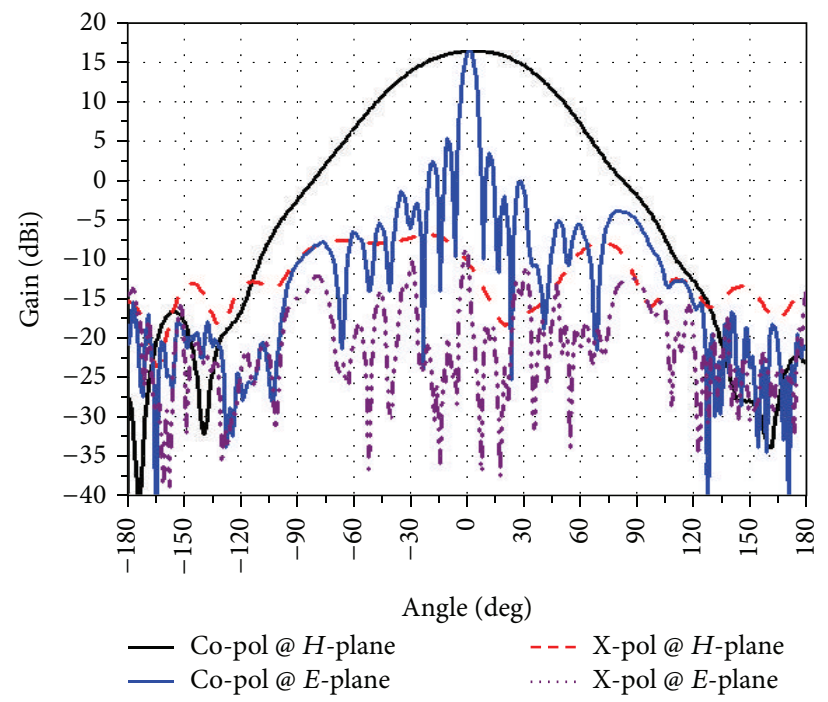

(f)

Figure 9: Continued. 


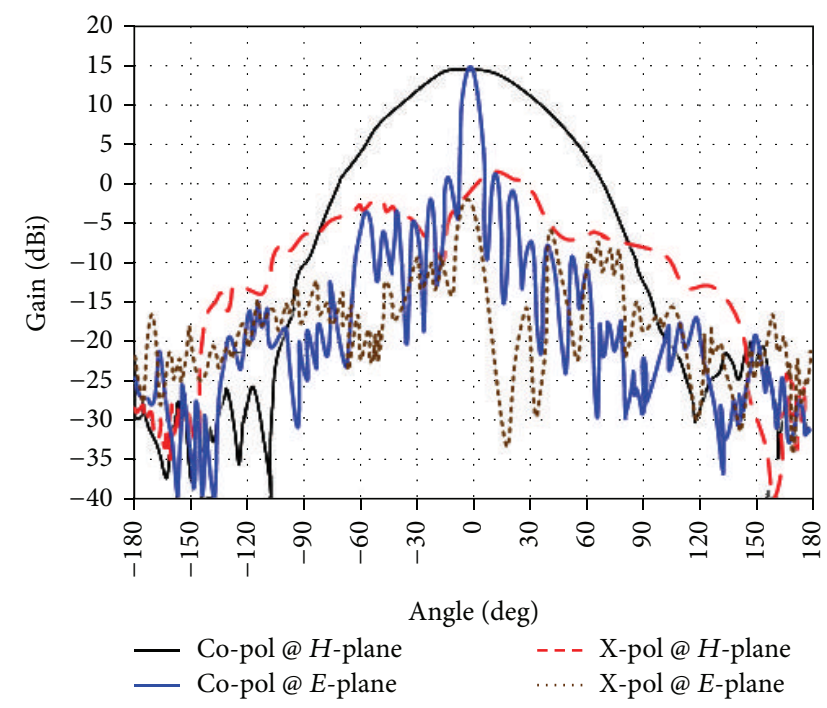

(g)

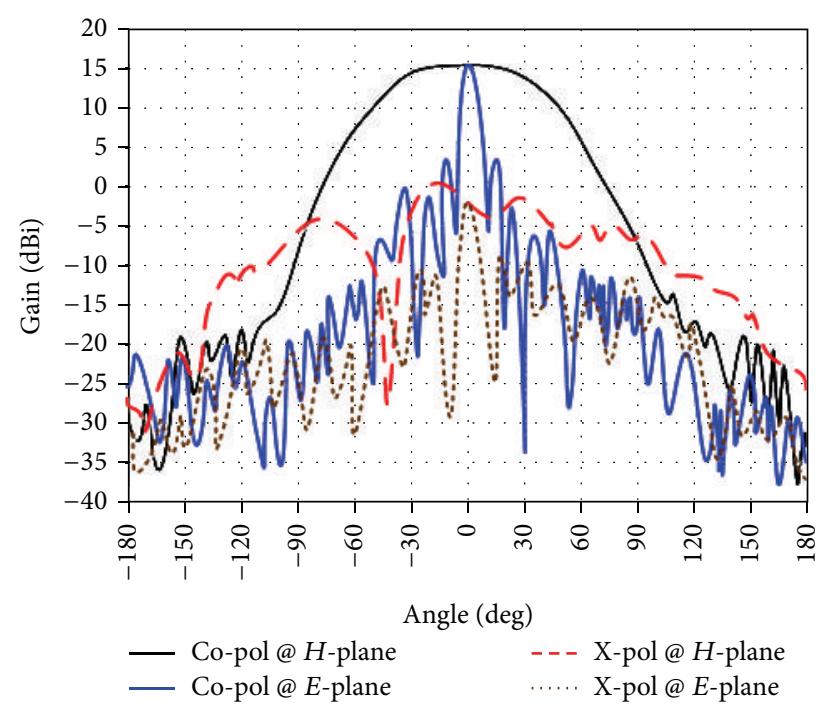

(h)

Figure 9: Measured radiation patterns of the multiband array: (a) $0.881 \mathrm{GHz}$ for TX of Band 1, (b) $0.837 \mathrm{GHz}$ for RX of Band 1, (c) $2.14 \mathrm{GHz}$ for TX of Band 2, (d) $1.95 \mathrm{GHz}$ for RX of Band 2, (e) $2.30 \mathrm{GHz}$ for Band 3, (f) $2.35 \mathrm{GHz}$ for Band 3, (g) $5.15 \mathrm{GHz}$ for Band 4, and (h) $5.50 \mathrm{GHz}$ for Band 4.

TABLE 3: Summary of minimum measured performances of the multiband base-station antenna.

\begin{tabular}{|c|c|c|c|c|c|c|c|}
\hline Operating band & Gain $[\mathrm{dBi}]$ & SLL $[\mathrm{dB}]$ & $\mathrm{BW}(\mathrm{El})\left[^{\circ}\right]$ & $\mathrm{BW}(\mathrm{Az})\left[^{\circ}\right]$ & Cross-pol. $[\mathrm{dB}]$ & $\mathrm{F} / \mathrm{B}$ ratio $[\mathrm{dB}]$ & Size $[\mathrm{mm}] /$ weight $[\mathrm{Kg}]$ \\
\hline \multicolumn{8}{|c|}{ Band 1} \\
\hline TX & 17.1 & 12.2 & 7.0 & 63.8 & 24.5 & 30.2 & \\
\hline $\mathrm{RX}$ & 17.0 & 12.3 & 7.8 & 64.7 & 25.0 & 31.8 & \\
\hline \multicolumn{8}{|l|}{ Band 2} \\
\hline $\mathrm{TX}$ & 17.0 & 12.0 & 5.0 & 47.5 & 26.4 & 30.2 & \\
\hline $\mathrm{RX}$ & 16.3 & 13.7 & 5.5 & 50.4 & 25.4 & 32.7 & $2480(\mathrm{~L}) \times 220(\mathrm{~W}) \times 95(\mathrm{H}) / 28.5$ \\
\hline \multicolumn{8}{|l|}{ Band 3} \\
\hline $\mathrm{T} / \mathrm{RX}$ & 16.6 & 10.1 & 4.9 & 45.2 & 31.8 & 32.5 & \\
\hline \multicolumn{8}{|l|}{ Band 4} \\
\hline $\mathrm{T} / \mathrm{RX}$ & 14.0 & 11.8 & 6.5 & 71.1 & 15.0 & 35.4 & \\
\hline
\end{tabular}

${ }^{*}$ SLL: Side-Lobe Level, BW: 3-dB beamwidth, and F/B: front-to-back.

\section{Acknowledgments}

The authors would like to express their gratitude to Y. H. Lee and other members of ACE Antenna Inc. for their valuable advice and contributions to the antenna development. This research was supported by the MSIP (Ministry of Science, ICT and Future Planning), Korea, under the Global IT Talent Support Program (NIPA-2014-H0904-14-1002) supervised by the NIPA (National IT Industry Promotion Agency) and the research fund of Hanbat National University in 2013.

\section{References}

[1] P. L. Starke and G. G. Cook, "Optimised design of multiband cellular base station antenna array for GSM and UMTS deployment," IET Microwaves, Antennas \& Propagation, vol. 3, no. 2, pp. 333-347, 2009.

[2] N. Chiba, T. Amano, and H. Iwasaki, "Dual-frequency planar antenna for handsets," Electronics Letters, vol. 34, no. 25, pp. 2362-2363, 1998.
[3] Z. D. Liu and P. S. Hall, "Dual-band antenna for hand held portable telephones," Electronics Letters, vol. 32, no. 7, pp. 609610, 1996.

[4] S. D. Targonski and D. M. Pozar, "Dual-band dual polarised printed antenna element," Electronics Letters, vol. 34, no. 23, pp. 2193-2194, 1998.

[5] F. J. Villegas, T. Cwik, Y. Rahmat-Samii, and M. Manteghi, "A parallel electromagnetic genetic-algorithm optimization (ego) application for patch antenna design," IEEE Transactions on Antennas and Propagation, vol. 52, no. 9, pp. 2424-2435, 2004.

[6] H. F. Abutarboush, R. Nilavalan, S. W. Cheung et al., "A reconfigurable wideband and multiband antenna using dualpatch elements for compact wireless devices," IEEE Transactions on Antennas and Propagation, vol. 60, no. 1, pp. 36-43, 2012.

[7] M. T. Islam, M. N. Shakib, and N. Misran, "Design analysis of high gain wideband L-probe fed microstrip patch antenna," Progress in Electromagnetics Research, vol. 95, pp. 397-407, 2009.

[8] S. Lee and Y. Sung, "A compact triple band antenna for a wireless USB dongle," Journal of Electromagnetic Engineering and Science, vol. 12, no. 2, pp. 185-188, 2012. 
[9] D. Piazza, N. J. Kirsch, A. Forenza, R. W. Heath, and K. R. Dandekar, "Design and evaluation of a reconfigurable antenna array for MIMO systems," IEEE Transactions on Antennas and Propagation, vol. 56, no. 3, pp. 869-881, 2008.

[10] J.-W. Baik, S. Pyo, T.-H. Lee, and Y.-S. Kim, "Switchable printed Yagi-Uda antenna with pattern reconfiguration," ETRI Journal, vol. 31, no. 3, pp. 318-320, 2009.

[11] Y.-C. Lee and J.-S. Sun, "Compact printed slot antennas for wireless dual- and multi-band operations," Progress in Electromagnetics Research, vol. 88, pp. 289-305, 2008.

[12] W. H. Weedon, W. J. Payne, and G. M. Rebeiz, "MEMS-switched reconfigurable antennas," in Proceedings of the IEEE Antennas and Propagation Society International Symposium, vol. 3, pp. 654-657, IEEE, Boston, Mass, USA, July 2001.

[13] C. won Jung, M. J. Lee, G. P. Li, and F. de Flaviis, "Reconfigurable scan-beam single-arm spiral antenna integrated with RFMEMS switches," IEEE Transactions on Antennas and Propagation, vol. 54, no. 2, pp. 455-463, 2006.

[14] Z. N. Chen, "Development of ultra-wideband antennas," Journal of Electromagnetic Engineering and Science, vol. 13, no. 2, pp. 6372, 2013.

[15] D. M. Pozar and S. D. Targonski, "A shared-aperture dualband dual-polarized microstrip array," IEEE Transactions on Antennas and Propagation, vol. 49, no. 2, pp. 150-157, 2001.

[16] N. Herscovici, C. Christodoulou, Z. Zaharis, E. Vafiadis, and J. N. Sahalos, "On the design of a dual-band base station wire antenna," IEEE Antennas and Propagation Magazine, vol. 42, no. 6, pp. 144-151, 2000.

[17] A. Thielens, G. Vermeeren, D. Kurup, W. Joseph, and L. Martens, "Compliance boundaries for multiple-frequency base station antennas in three directions," Bioelectromagnetics, vol. 34, no. 6, pp. 465-478, 2013.

[18] T. Wu, R. L. Li, S. Y. Eom et al., "Switchable quad-band antennas for cognitive radio base station applications," IEEE Transactions on Antennas and Propagation, vol. 58, no. 5, pp. 1468-1476, 2010.

[19] R. Gabriel and M. Gottl, "Dual-polarized Dipole Antenna," United States Patent US 6,313,809, 2001.

[20] J. S. Park and J. S. Jin, "Dual polarization broadband antenna having with single pattern," International Application PCT/KR2007/001597, 2007.

[21] T. Suda, T. Takano, and Y. Kazama, "Grating lobe suppression in an array antenna with element spacing greater than a half wavelength," in Proceedings of the IEEE Antennas and Propagation Society International Symposium (APSURSI'10), pp. 1-4, Toronto, Canada, July 2010. 

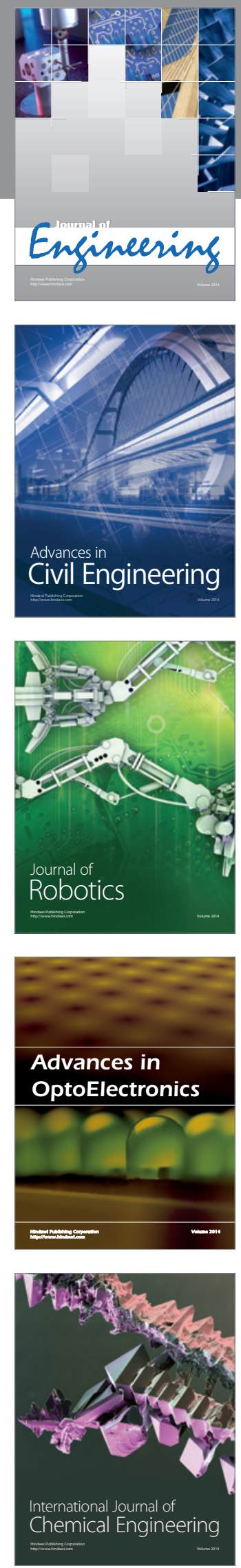

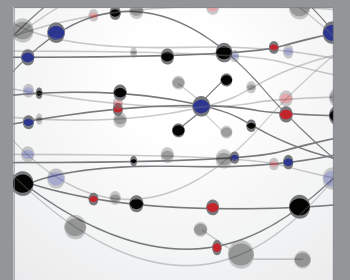

The Scientific World Journal
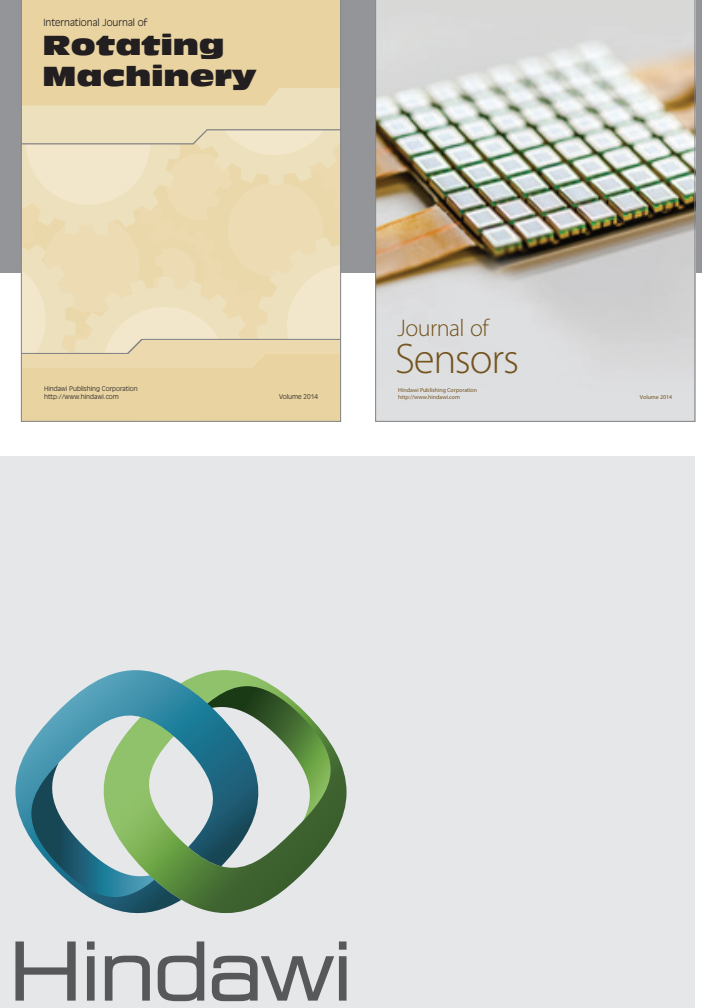

Submit your manuscripts at http://www.hindawi.com
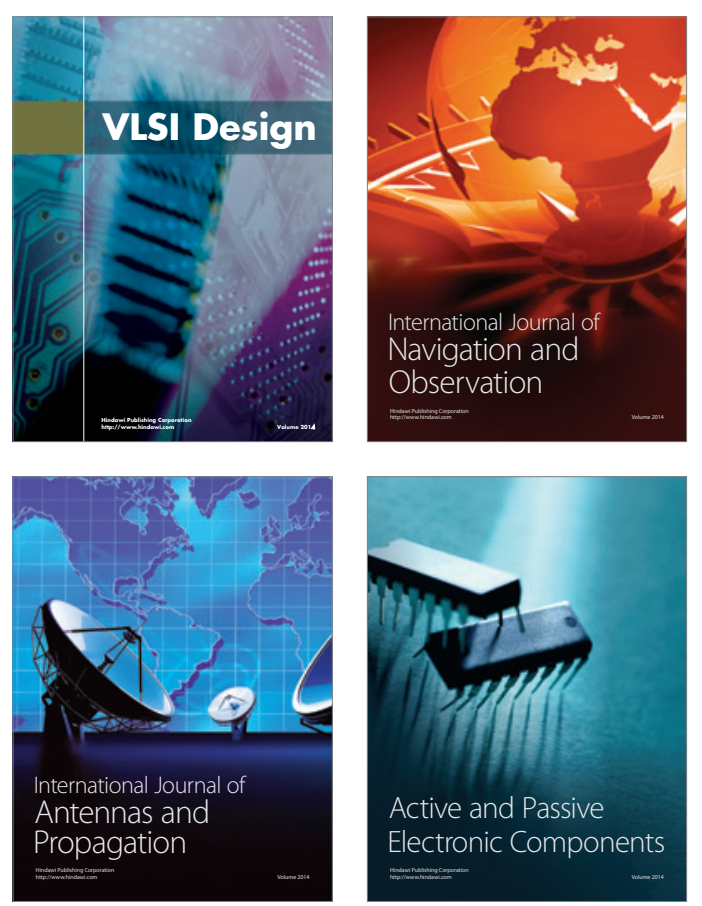
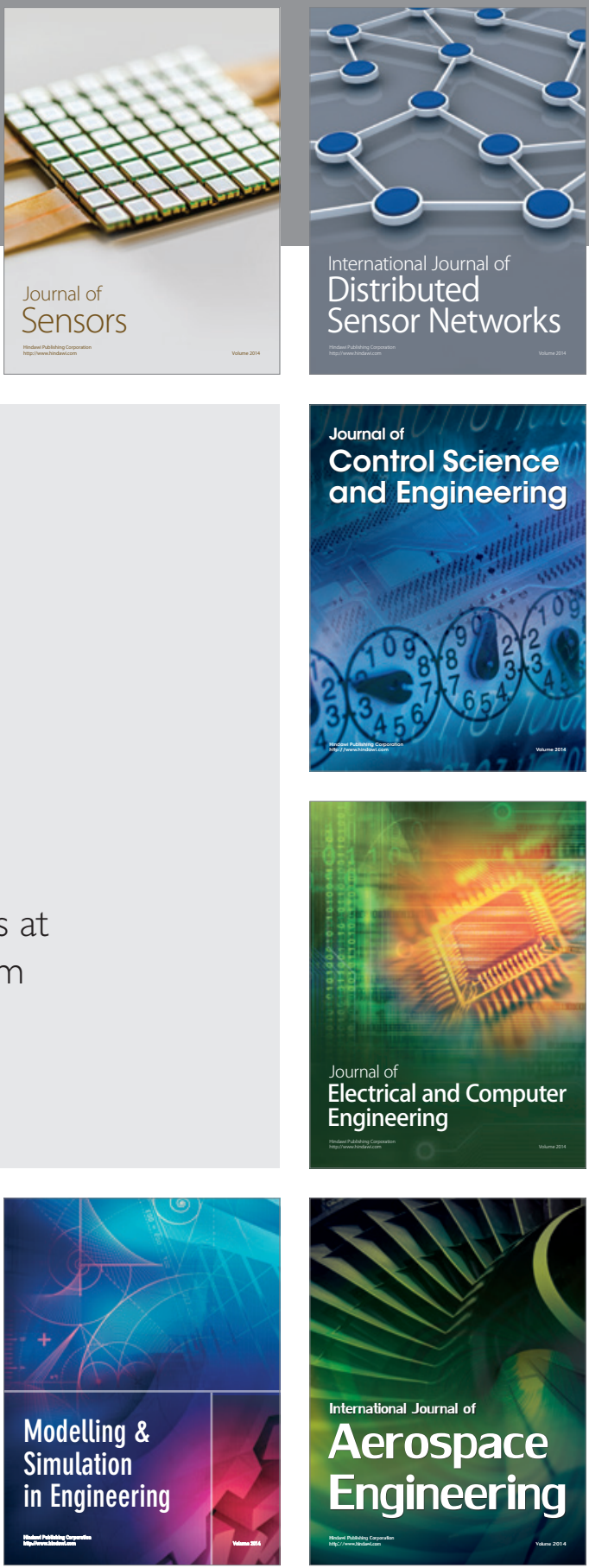

Journal of

Control Science

and Engineering
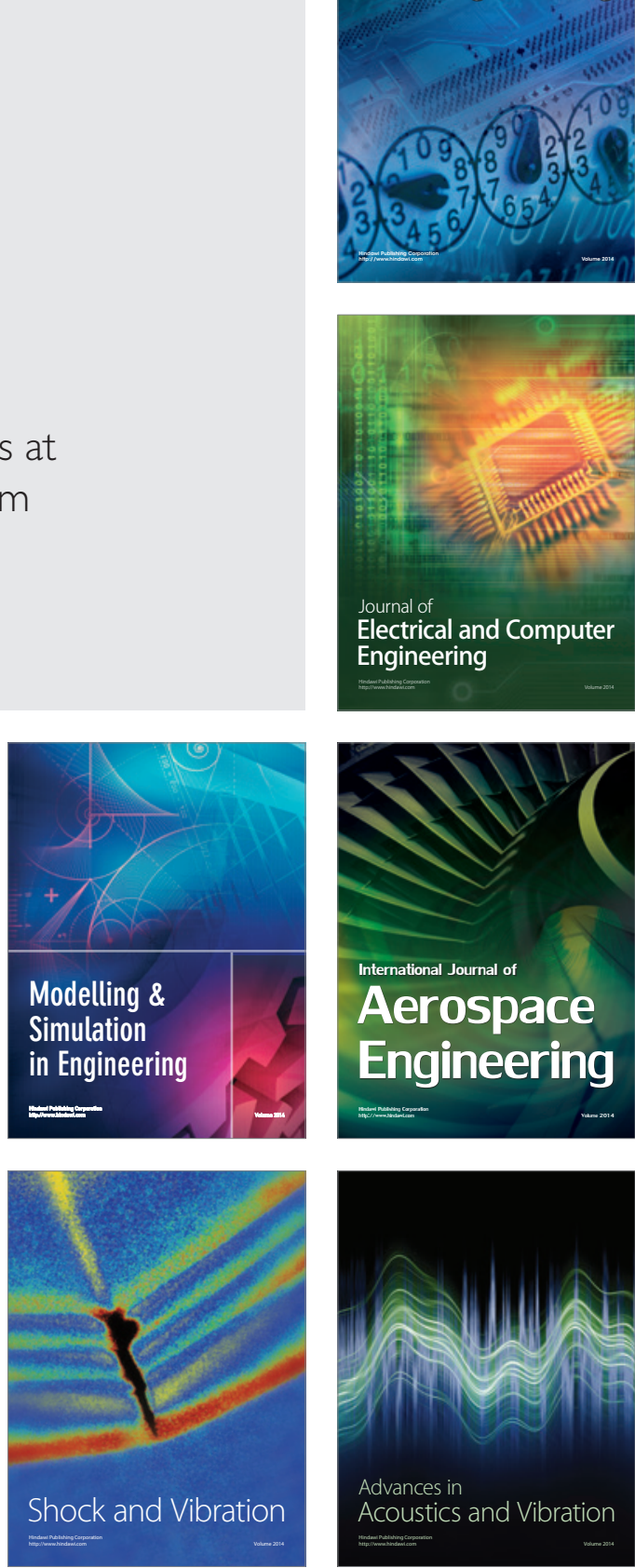